Gleason theo ISUP của ung thư tuyến tiền liêt trên giải phẫu bệnh có mối tương quan có ý nghĩa thống kê. Trong tương lai, chúng tôi sẽ thực hiện nghiên cứu trên cõ̃ mẫu lớn hơn nhằm đánh giá đầy đủ, chi tiết hơn vai trò của cộng hưởng từ đa thông số trong phát hiện ung thư tuyến tiền liệt có ý nghĩa lâm sàng.

\section{TÀI LIÊU THAM KHẢO}

1. Sung H., Ferlay J., Siegel R.L., et al. (2020). Global cancer statistics 2020: GLOBOCAN estimates of incidence and mortality worldwide for 36 cancers in 185 countries. CA Cancer J Clin.

2. Peter R., J. Kellogg P., Geoffrey B., et al. (2021). Prostate cancer early detection Version 1.2021. National Comprehensive Cancer Network. 68, 7.

3. European society of Urogenital Radiology. (2019). Revisions in PI-RADS v2.1. American College of Radiology. 29.

4. Tamada T. (2019). Comparison of PI-RADS version 2 and PI-RADS version 2.1 for the detection of transition zone prostate cancer. Eur J Radiol, 6.

5. Mythreyi C., Lauren H., Dipleen K., et al. (2019). Prostate Imaging - Reporting and Data System 2019 Version 2.1. ACR-ESUR-AdMeTech 2019. 76.

6. Walker S.M., Mehralivand S., Harmon S.A., et al. (2020). Prospective Evaluation of PI-RADS Version 2.1 for Prostate Cancer Detection. Am J Roentgenol, 215(5), 1098-1103.

7. Patel P., Wang S., and Siddiqui M.M. (2019). The Use of Multiparametric Magnetic Resonance Imaging (mpMRI) in the Detection, Evaluation, and Surveillance of Clinically Significant Prostate Cancer (csPCa). Curr Urol Rep, 9.

8. Katz A., Liu C., and Kosinski K.E. (2016). Histopathologic correlation of PI-RADS V.2 lesions on 3T multiparametric prostate MRI. J Clin Oncol, 34(2), 10-10.

9. Alqahtani S., Wei C., Zhang Y., et al. (2020). Prediction of prostate cancer Gleason score upgrading from biopsy to radical prostatectomy using pre-biopsy multiparametric MRI PIRADS scoring system. Sci Rep, 10(1), 7722.

\title{
NGHIÊN CỨU ĐÁNH GIÁ MộT SỐ ĐĂC TÍNH VÂT LÝ VÀ KHẢ NĂNG GIẢI PHÓNG DƯợC CHẤT QUA DA CHUỘT CỦA VI NHŨ TƯƠNG METHYL SALICYLAT
}

\section{TÓM TẮT}

Trong nghiên cứu này, vi nhũ tương methyl salicylat $5 \%$ tiếp tuc được nghiên cứu và đánh giá về các tiêu chí như hình thức, kích thước tiểu phân và phân bố kích thước tiểu phân, chỉ số khúc xạ, hình thái và khả năng giải phóng dược chất qua da lưng chuôt nhắt. Kết quả cho thấy, vì nhũ tương có hình thức đồng nhất, trong suốt, không màu, các giọt kích thước tiểu phân khoảng $20 \mathrm{~nm}$, khoảng phân bố kích thước PDI nhỏ hơn 0,2. Chỉ số khúc xa của các mẫu vi nhũ tương methyl salicylat nằm trong khoảng 1,415 1,428. Phân trăm methyl salicylat giải phóng qua da chuột từ mẫu vi nhũ tương $\mathrm{A} 1$ và $\mathrm{A} 1^{\prime}$ tăng nhanh trong $6 \mathrm{~h}$ đầu và cao hơn 1,3 lần so với thuốc mõ methyl salicylat. Như vậy vi nhũ tương methyl salicylat là hệ mang thuốc qua da tiềm năng sử dụng trong giảm đau cấp.

Tư khóa: vi nhũ tương, methyl salicylat, hệ đưa thuốc qua da, giải phóng dược chất

\section{SUMMARY \\ CHARACTERIZATION AND DRUG RELEASE STUDY ON MOUSE SKIN OF METHYL}

\footnotetext{
*Trường Đại học Dược Hà Nội

Chiu trách nhiệm chính: Trần Thi Hải Yến

Email: tranyendhd@gmail.com

Ngày nhận bài: 7.01.2021

Ngày phản biên khoa học: 10.3.2021

Ngày duyệt bài: 18.3.2021
}

\section{Trần Thị Hải Yến*, Hoàng Thục Oanh* SALICYLATE MICROEMULSION}

This study aims to characterize microemulsion loaded with methyl salicylate $5 \%$ for particles size and distribution, refractive index, morphology and released drug through the mouse skin. The results showed that the microemulsion has transparent, colorless appearance, the particles size were about $20 \mathrm{~nm}$, the PDI was less than 0.2 . The refractive index of methyl salicylate microemulsion ranged from 1.415 to 1.428 . Percentage of released methyl salicylate through the mouse skin from $A 1$ and $A 1^{\prime}$ microemulsions increased rapidly in the first 6 hours and were higher than methyl salicylate ointment by 1.3 times. Methyl salicylate microemulsion is potential transdermal drug delivery system for use in acute pain relief.

Keywords: microemulsion, methyl salicylate, transdermal drug delivery,

\section{I. ĐĂT VẤN ĐỀ}

Methyl salicylat (MS) là hoạt chất thuộc nhóm NSAIDS, thường được đưa vào các dạng thuốc dùng ngoài da như thuốc mõ, gel, miếng dán... để điều trị, giảm đau các bệnh về cơ, khớp. Vi nhũ tương (VNT) là một trong những hệ mang thuốc tiềm năng do có nhiều ưu điểm như kích thước tiểu phân của hệ chỉ cõ vài chục nano, có thể chất đẹp, trong suốt, phương pháp bào chế đơn giản, dễ áp dụng trong sản xuất. Ở nghiên cứu trước nhóm tác giả đã khảo sát xây dựng công thức vi nhũ tương methyl salicylat $1 \%$ và 
$5 \%$ sử dụng pha dâu là isopropyl mirystat, chất diện hoạt (CDH) Tween80, chất đồng diện hoạt (CĐDH) Transcutol P. Trong đó VNT methyl salicylat $5 \%$ có kích thước tiểu phân nhỏ và ổn định trong khoảng thời gian khảo sát [1]. Trong nghiên cứu này, một số đặc tính của VNT như hình thức, kích thước tiểu phân, chỉ số khúc xạ, hình thái cấu trúc và khả năng giải phóng của dược chất qua da chuột tiếp tục được nghiên cứu đánh giá.

\section{NGUYÊN UỆU VÀ PHƯƠNG PHÁP NGHIÊN CỨU}

\subsection{Nguyên vật liệu:}

Nguyên liệu: Methyl salicylat, isopropyl myristat (IPM); Tween 80 có nguồn gốc Trung Quốc; Transcutol P có xuất xứ Hàn Quốc; ethanol tuyệt đối được cung cấp từ công ty hóa chất Đức Giang, Việt Nam; nước thẩm thấu ngược được điều chế ở phòng thí nghiệm, Việt Nam.

Thiêt bị: thiết bị phân tích kích thước Zetasizer ZS90 (Malvern, Anh), máy đo độ khúc xạ Kruss Optronic (Đức), thiết bị đánh giá giải phóng qua màng Hanson Research (Mỹ), kính hiển vi điện tử truyền qua Jeol (Nhật Bản).

Động vật thí nghiệm: Chuột nhắt trắng, đực, khoẻ mạnh, cân nặng từ $25-30 \mathrm{~g}$ do Viện kiểm nghiệm thuốc trung ương cung cấp.

\subsection{Phương pháp nghiên cứu}

\subsubsection{Phương pháp bào chế vi nhũ} tương methyl salicylat

Vi nhũ tương được bào chế bằng cách sau: hòa tan MS trong dung môi dầu theo tỉ lệ MS: dung môi dầu $=1: 2(\mathrm{kl} / \mathrm{kl})$ lắc xoáy tạo thành pha dầu đồng nhất. Hỗn hợp Smix gồm chất diện hoạt (Tween 80 ) và chất đồng diện hoạt theo tỉ lệ $(\mathrm{kl} / \mathrm{kl})$ được trộn lẫn và lắc xoáy tạo hỗn hợp đồng nhất. Phối hợp Smix vào pha dầu lắc xoáy hoặc khuấy từ tạo hỗn hợp đồng nhất (hỗn hợp $\mathrm{A}$ ). Thêm nước vào hổn hợp $\mathrm{A}$ và khuấy từ để tạo vi nhũ tương [2].

2.2.2 Bào chế thuốc mỡ methyl salicylat $5 \%$. Thuốc mõ methyl salicylat $5 \%$ với vai trò là chế phẩm đối chiếu được bào chế theo công thức dưới đây:

\begin{tabular}{|c|c|}
\hline Methyl salicylate & $0,5 \mathrm{~g}$ \\
\hline Lanolin & $2,5 \mathrm{~g}$ \\
\hline Vaselin & $7 \mathrm{~g}$ \\
\hline
\end{tabular}

Đun chảy hỗn hợp tá dược lanolin, vaselin trong lọ thủy tinh có nắp, đun chảy cách thủy, thêm methyl salicylat vào, đậy nắp và lắc đến đồng nhất, để nguội đến nhiệt độ phòng thu được thuốc mõ đồng nhất.
2.2.3 Đánh giá một số đặc tính của vi nhũ tương methyl salicylat

Theo nghiên cứu trước [1], 3 công thức vi nhũ tương methyl salicylat $5 \%$ có thành phần như bảng 1 có hình thức, KTTP và phân bố KTTP ổn định trong thời gian nghiên cứu. Do đó được tiếp tục nghiên cứu đánh giá một số các đặc tính của vi nhũ tương.

Bảng 1. Thành phân của công thức vi nhũ tương methyl salicylat 5\%

\begin{tabular}{|c|c|c|c|}
\hline Công thức & $\mathrm{A} 1$ & $\mathrm{~A} 2$ & $\mathrm{~A}^{\prime}$ \\
\hline $\mathrm{MS}(\mathrm{g})$ & 5,0 & 5,0 & 5,0 \\
\hline $\mathrm{IPM}(\mathrm{g})$ & 10,0 & 10,0 & 10,0 \\
\hline Tween $80(\mathrm{~g})$ & 36,0 & 30,0 & 30,0 \\
\hline Transcutol P $(\mathrm{g})$ & 24,0 & 20,0 & 30,0 \\
\hline Nước tinh khiết $(\mathrm{g})$ & 25,0 & 35,0 & 25,0 \\
\hline
\end{tabular}

2.2.3.1. Hinh thức. Vi nhũ tương tạo thành sau bào chế trong suốt hoặc trong mờ, đồng nhất, không có tiểu phân quan sát được bằng mắt thường

2.2.3.2. Chỉ số khúc xạ (RI). Chỉ số khúc xạ của các mẫu được đo 3 lấn sử dụng máy đo độ khúc xạ tự động Kruss Optronic và lấy giá trị trung bình. Nhiệt độ đo $25^{\circ} \mathrm{C} \pm 2{ }^{\circ} \mathrm{C}$.

2.2.3.3. Kích thước tiểu phân trung binh (KTTP), phân bố kích thước tiểu phân. Kích thước tiểu phân được xác định bằng phương pháp tán xạ ánh sáng động (Dynamic light scattering - DLS). Nguyên lý của phương pháp là khi chiếu chùm tia lase vào các hạt có kích thước khác nhau sẽ thu được mức độ tán xạ ánh sáng khác nhau. Dựa vào độ tán xạ của chùm tia sau khi va chạm vào hạt ta có thể tính được kích thước hat theo thuyết Mie. Độ đồng nhất của phân bố KTTP được biểu diễn bằng hệ số đa phân tán (Polydispersity Index - PDI). Giá trị PDI trong khoảng $0,1-0,25$ chứng tỏ sự phân bố hẹp của KTTP, trong khi giá trị PDI lớn hơn 0,5 thể hiện sự phân bố rộng của KTTP. Sử dụng máy phân tích kích thước hat Zetasizer Nano ZS90 đo KTTP và PDI. Mỗi mẫu được đo trong điều kiện pha loãng 10 lần với nước cất, đo 3 lần sau đó tính trung bình và độ lệch chuẩn.

2.2.3.4. Hinh thái của vi nhũ tương. Hình thái mẫu vi nhũ tương được chụp sử dụng kính hiển vi điện tử truyền qua (TEM). Các tia điện tử với năng lượng cao được truyền qua mẫu vật mỏng (dưới 200nm). Sau sự tương tác của điên tử truyền qua với mẫu vật, ảnh được hình thành, phóng đại và hội tụ trên các vật liệu mang ảnh hoặc được ghi lại bởi máy ghi hình. Ưu điểm của 
phương pháp chụp TEM là độ phóng đại khá lớn và cung cấp đồng thời hình ảnh và thông tin nhiễu xạ của mẫu vật. Mẫu vi nhũ tương được nhỏ lên lưới đồng bao cacbon và nhuộm bằng acid osmic nhằm tăng độ tương phản của mẫu.

2.2.4. Đánh giá khả năng giải phóng dược chất qua da của VNT methyl salicylat $\mathbf{5 \%}$ bằng thử nghiêm ex-vivo. Lượng dược chất giải phóng qua da trong 24 giờ được đánh giá bằng sử dụng màng da lưng chuột nhắt để so sánh khả năng giải phóng dược chất qua da trong 24 giờ của thuốc mõ methyl salicylat $5 \%$ và VNT methyl salicylat $5 \%$.

Màng khuếch tán là da lưng chuột nhắt đực, khoẻ mạnh, khối lượng từ 25-30g được loại lông, tách riêng, làm sạch lớp mõ dưới da bằng dao và kéo phẫu thuật, rửa bằng nước muối sinh lý để loại sạch lông và tạp bẩn, bảo quản ở $2-8^{\circ} \mathrm{C}$ trong 2 ngày. Trước khi thử, màng da lưng được hoạt hoá bằng dung dịch nước muối sinh lí trong 30 phút. Qua tham khảo tài liệu [6] thử nghiệm được tiến hành trên hệ thống thử giải phóng qua màng Hanson Research với các điều kiện như: môi trường khuếch tán là $7 \mathrm{ml}$ dung dịch salin đệm phosphat pH 7,4; diện tích thử $1,767 \mathrm{~cm}^{2}$; nhiệt độ thử: $32^{\circ} \mathrm{C} \pm 0,5$; tốc độ khuấy 400 vòng/phút; khối lượng mẫu thử khoảng $0,1 \mathrm{~g}$ VNT hoặc thuốc mõ, tương đương 5mg dược chất.

Tại thời điểm $t=0$, cân $0,1 \mathrm{~g}$ vi nhũ tương vào ngăn cho. Lây mẫu ở các thời điểm $t=1,2,4,6$, 8,24 giờ. Thể tích mỗi lần lấy mẫu là $0,5 \mathrm{ml}$, sau đó thêm một thể tích môi trường giải phóng vào ngăn nhận bằng đúng thể tích đã lấy ra. Mẫu môi trường được lây ra đem định lượng bằng phương pháp HPLC với các thông số như mô tả ở trên.

Công thức tính \% lượng dược chất thấm qua da tai thời điểm t:

$$
\% D C_{g p}=\frac{1}{m_{t}} \times\left(C_{t} \times 7+\mathrm{v} \times \sum_{\mathrm{i}=1}^{\mathrm{t}-1} C_{i}\right) \times 100 \%
$$

Trong đó: $\% \mathrm{DC}_{\mathrm{gp}}$ : \% dược chất giải phóng so với lượng dược chất trong VNT đem thử (\%).

$\mathrm{C}_{\mathrm{t}}, \mathrm{C}_{\mathrm{i}}$ : nồng độ dược chất trong môi trường khuếch tán tại thời điểm $t$ và $i(\mu \mathrm{g} / \mathrm{ml})$.

v: thể tích mẫu lấy tại từng thời điểm $(\mathrm{ml})$

$\mathrm{mt}$ : lượng methyl salicylat có trong mẫu VNT đem thử $(\mu \mathrm{g})$.

\section{KẾT QUẢ VÀ BÀN LUÂ̂N}

3.1. Về Hình thức, KTTP trung bình và phân bố KTTP (PDI). Các mẫu VNT 5\% có hình thức trong suốt, nhớt, đồng nhất; sau khi pha loãng 10 lần với nước các mẫu vấn trong suốt, đồng nhất nhưng độ nhớt giảm và có ánh xanh.

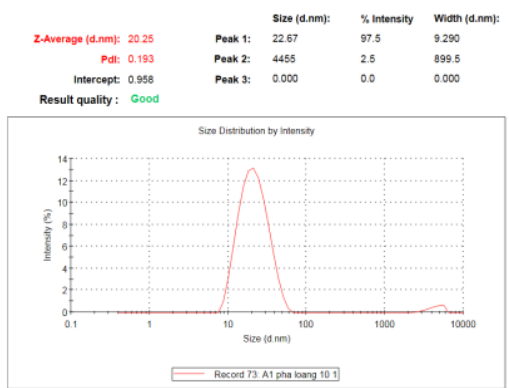

(A)

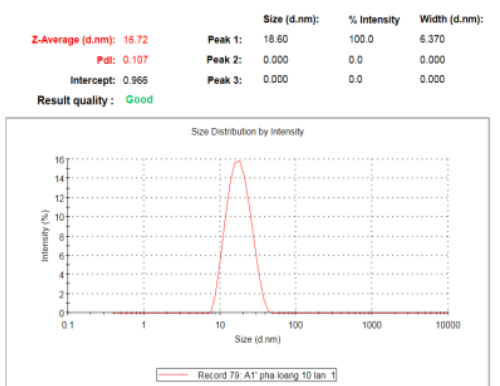

(B)

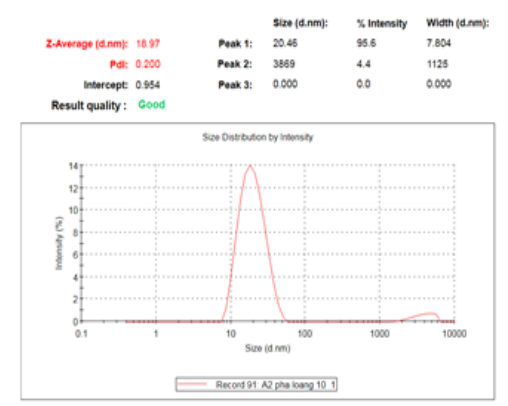

(C)

Hinh 1. KTTP, PDI của các mẫu A1 (hinh $A$ ), $A 1^{\prime}$ (hình B) và A2 (hinh $C$ )

Các đồ thi ở hình 1 cho thây, KTTP của các mẫu VNT nhỏ, chỉ khoảng $20 \mathrm{~nm}$. Đồ thị phân bố kích thước của các mẫu vi nhũ tương nghiên cứu đều có 1 peak chính khoảng 20 nm; PDI trong khoảng $0,1-0,2$ cho thấy phân bố kích thước hẹp hay nói cách khác khoảng phân bố kích thước hẹp. Tuy nhiên trên đồ thị phân bố KTTP của mẫu $A 1$ và $A 2$ thấy xuất hiện thêm peak lớn khoảng vài nghìn nm là do có thể mẫu đo bị lẫn tạp chất ngoại lai.

3.2. Hình thái câu trúc. Qua hình ảnh chụp TEM ở hình 2, quan sát thây các tiểu phân đều có dạng hình cầu, kích thước khoảng 10 nanomet, có thể tụ lại với nhau thành đám.

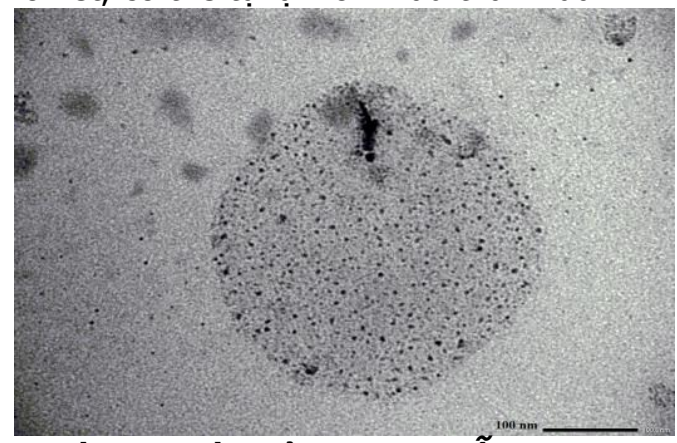

Hình 2. Hình ảnh TEM mẫu VNT A2 
3.3. Chỉ số khúc xạ. Chỉ số khúc xạ của các thành phần trong công thức và của 3 mẫu VNT methyl salicylat $5 \%$ được thể hiện ở bảng 2.

Bảng 2. Kêt quả chi số khúc xạ của các thành phần và VNT methyl salicylat 5\%

\begin{tabular}{|c|c|c|c|c|c|c|c|c|}
\hline & MS & IPM & Tween 80 & Transcutol P & $\mathrm{H}_{2} \mathrm{O}$ & $\mathrm{A} 1$ & $\mathrm{~A} 2$ & $\mathrm{~A} 1^{\prime}$ \\
\hline RI & 1,5327 & 1,4309 & 1,4699 & 1,4225 & 1,3308 & 1,4272 & 1,4152 & 1,4243 \\
\hline
\end{tabular}

Kết quả cho thấy, các mấu vi nhũ tương methyl salicylat có chỉ số khúc xạ nằm trong khoảng 1,415 - 1,427, lớn hơn chỉ số khúc xạ của nước và nhỏ hớn chỉ số khúc xạ của methyl salicylat, IPM và Tween 80.

3.4. Khả năng giải phóng dược chất qua da chuột của VNT methyl salicylat $5 \%$ bằng thử nghiệm ex-vivo. Mức độ giải phóng dược chất qua da chuột nhắt của các công thức VNT $A 1, A 2, A 1$ ' và thuốc mõ methyl salicylat $5 \%$ được thể hiện ở bảng 3 và hình 3 dưới đây.

Bảng 3. Phần trăm dược chất giải phóng của các mẫu VNT và thuốc mõ̃ methyl salicylat 5\%

\begin{tabular}{|c|c|c|c|c|}
\hline \multirow{2}{*}{$\begin{array}{c}\text { Thời gian } \\
\text { (h) }\end{array}$} & \multicolumn{4}{|c|}{ Phân trăm dược chất giải phóng \% (TB $\mathbf{\text { SDD }}$} \\
\cline { 2 - 5 } & Mấu A1 & Mấu A2 & Mấu A1' & Thuốc mõ MS 5\% \\
\hline 1 & $4,67 \pm 2,01$ & $7,06 \pm 0,12$ & $5,57 \pm 2,11$ & $2,22 \pm 0,49$ \\
\hline 2 & $8,75 \pm 4,60$ & $12,96 \pm 1,20$ & $9,59 \pm 1,29$ & $5,34 \pm 1,49$ \\
\hline 4 & $19,86 \pm 7,05$ & $20,85 \pm 3,12$ & $22,28 \pm 2,14$ & $14,75 \pm 2,41$ \\
\hline 6 & $29,19 \pm 5,72$ & $23,23 \pm 1,63$ & $29,52 \pm 3,02$ & $22,29 \pm 2,65$ \\
\hline 8 & $29,99 \pm 5,52$ & $25,35 \pm 2,12$ & $29,97 \pm 3,28$ & $29,31 \pm 2,69$ \\
\hline 24 & $37,82 \pm 3,36$ & $37,72 \pm 2,32$ & $31,04 \pm 3,68$ & $54,73 \pm 0,04$ \\
\hline
\end{tabular}

Các mầu VNT $A 1, A 1^{\prime}, A 2$ có đồ thị giải phóng dược chất qua da tương tự nhau. Mẫu VNT A1 và $A 1^{\prime}$ cho lượng dược chất giải phóng cao hơn mẫu VNT $A 2$, cụ thể tại thời điểm $6 \mathrm{~h}$ phần trăm giải phóng dược chất từ $A 1(29,19 \%)$ và $\mathrm{A1}^{\prime}$ $(29,52 \%)$ gấp khoảng 1,3 lần phần trăm giải phóng của A2. Như vậy, công thức có tỉ lệ Smix $=60 \%$ cho lượng dược chất giải phóng cao hơn so với tỉ lệ Smix $=50 \%$.

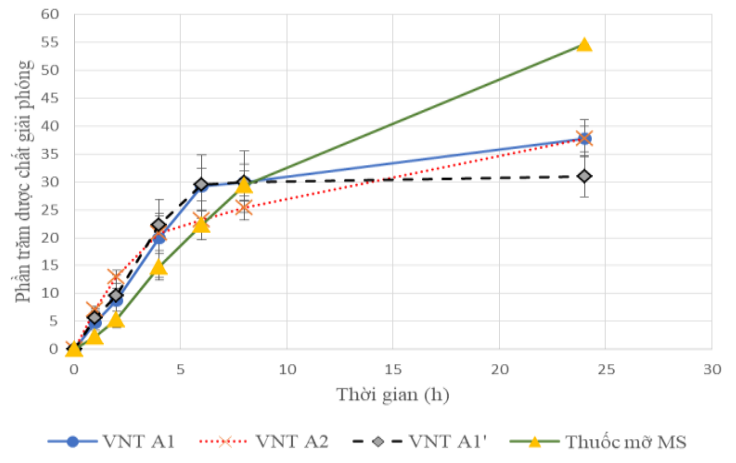

Hình 3. Khả năng giải phóng dược chât qua da của các công thức VNT methyl salicylat và thuốc mõ methyl salicylat 5\%.

Các mẫu VNT cho phần trăm dược chất giải phóng cao hơn mẫu thuốc mõ trong khoảng 6 giờ đâu. Tại thời điểm $4 \mathrm{~h}$, phần trăm dược chất giải phóng từ mẫu $A 1, A 2, A 1$ ' lần lượt gấp 1,35; 1,$41 ; 1,51$ lần phần trăm dược chất giải phóng tữ mẫu thuốc mõ. Tại thời điểm $6 \mathrm{~h}$, phần trăm giải phóng của $A 1(29,19 \%), A 1^{\prime}(29,52 \%)$ gấp 1,31 lần \% giải phóng thuốc mõ (22,29\%), trong khi mẫu A2 cho lượng dược chất giải phóng tương đương với mầu thuốc mõ. Tuy nhiên, từ 8h trở đi, lượng dược chất giải phóng từ các mẫu VNT thấp hơn mấu thuốc mõ̃, cụ thể sau $24 \mathrm{~h}$ lượng dược chất giải phóng từ các mẫu VNT chỉ đạt khoảng 30\% - 40\%, trong khi mẫu thuốc mõ cho lượng dược chất giải phóng đạt khoảng 54\%.

\section{BÀN LUÂ̂N}

Vi nhũ tương MS thu được có hình thức đồng nhất, trong suốt, khi pha loãng 10 lần bằng nước tinh khiết thu được dich đồng nhất có ánh xanh. Điều này có thể giải thích khi thêm nước, tạo các hat dầu kích thước cõ khoảng $20 \mathrm{~nm}$ (được đo với máy Zetasiser, nhỏ hơn bước sóng ánh sáng khả kiến) với mật độ đủ lớn, khi ánh sáng trắng chiếu vào mẫu, ánh sáng xanh da trời có bước sóng ngắn, hệ số tán xạ cao (theo phương trình hệ số tán xạ Rayleigh), tán xạ theo nhiều hướng đến mắt người quan sát (tán xạ Rayleigh), do đó mẫu có ánh xanh sau khi pha loãng [3].

Việc pha loãng các mấu VNT có thể làm thay đổi kích thước giọt VNT, hay cấu trúc của hệ VNT. Tuy nhiên, các mẫu VNT có nồng độ cao, khi tiến hành đo trực tiếp trên thiết bị xác định kích thước Zetasizer ZS90 sẽ gây sai số lớn. Do vậy, cần pha loãng các mẫu VNT để đạt count rate phù hợp từ $200-400$ pcs. Đồng thời, do kích thước VNT trong khoảng từ $10-200 \mathrm{~nm}$ nên cần pha loãng các mẫu đo để đạt được nồng độ khoảng từ $0,1-1 \mathrm{~g} / \mathrm{l}[4]$.

Ngoài ra, bằng cách sử dụng phương pháp chụp hiển vi điện tử truyền qua mẫu vi nhũ tương không pha loãng cho thấy kích thước giọt 
của VNT không pha loãng khoảng $10 \mathrm{~nm}$ có thể tụ với nhau. Kết quả đo bằng máy phân tích kích thước tiểu phân Zetasizer nano ZS90 bằng phương pháp tán xạ ánh sáng động cho KTTP trung bình khoảng $20 \mathrm{~nm}$. Phổ đồ phân bố KTTP của các mẫu VNT đều nằm trong khoảng hẹp. Sự khác biệt về KTTP của vi nhũ tương xác định bằng hai phương pháp khác nhau không nhiều, có thể nằm trong khoảng sai số của phép đo.

Chỉ số khúc xạ của các mẫu VNT nằm trong khoảng 1,415 - 1,427, lớn hơn chỉ số khúc xạ của nước và nhỏ hơn chỉ số khúc xạ của methyl salicylat, IPM và Tween 80 . Trong các thành phần cấu tạo nên vi nhũ tương thì nước có chỉ số khúc xạ thấp nhất là 1,33, tiếp theo là chỉ số khúc xạ của transcutol $\mathrm{P}(1,42)$; sau đó lần lượt là $\operatorname{IPM}(1,43)$ và Tween $80(1,47)$ và cuối cùng là MS có chỉ số khúc xạ cao nhất $(1,53)$. Các mẫu vi nhũ tương có phần trăm dược chất tương đương nhau là $5 \%$, khác nhau về tỉ lê $\mathrm{CDH}$ và CĐDH do đó cũng khác nhau về chỉ số khúc xa. Cụ thể, công thức $A 2$ có tỉ lệ $\mathrm{CDH}$ và $\mathrm{CĐDH}$ là $50 \%$ thấp hơn hai công thức $A 1$ và $A 1_{\tilde{n}}^{\prime}(60 \%)$, cỏ tỉ lệ nước đạt $35 \%$ cao hơn $25 \%$ ở mẫu $A 1$ và $\mathrm{A} 1^{\prime}$. Do đó chỉ số khúc xa của mẫu $\mathrm{A} 2$ thấp nhất trong 3 mẫu vi nhũ tương. Công thức $A 1$ và $A 1$ mặc dù có tỉ lệ nước như nhau (25\%), nhưng công thức $A 1$ có tỉ lệ Tween 80 cao hơn công thức $A 1^{\prime}$ và tỉ lệ Transcotol $P$ thấp hơn. Chính vì vậy, mẫu vi nhũ tương $A 1$ có chỉ số khúc xạ cao hớn mẫu $A 1^{\prime}$. Chỉ số khúc xạ của nhũ tương dầu/nước thường nhỏ hơn chỉ số khúc xa của vi nhũ tương nước/dầu vì tỹ lệ nước trong VNT dầu/nước thường lớn hơn. Trong nghiên cứu này, 3 mẫu VNT đều là kiểu dầu/nước nhưng tỉ lệ nước và các thành phần trong nhũ tương khác nhau nên chỉ số khúc xa cũng thay đổi. Với mẫu có tỉ lệ nước lớn hơn cả thì chỉ số khúc xạ thấp nhất.

Các mẫu VNT $A 1$ và $A 1^{\prime}$ cho phần trăm dược chất giải phóng cao hơn mấu thuốc mõ trong 6 giờ đầu, hay tốc độ giải phóng dược chất qua da chuột nhắt của VNT trong $6 \mathrm{~h}$ đầu cao hơn so với thuốc mõ methyl salicylat. Tuy nhiên, từ $8 \mathrm{~h}$ trở đi, lượng dược chất giải phóng từ các mẫu VNT thấp hơn mẩu thuốc mỡ. Điều này có thể giải thích do mẫu VNT có thể chất lỏng dễ bay hơi hơn thuốc mõ có thể chất bán rắn. Vi nhũ tương A2 có phần trăm giải phóng dược chất ở thời điểm $6 \mathrm{~h}$ thấp hơn hai mẫu vi nhũ tương $\mathrm{A} 1, \mathrm{A1}^{\prime}$ và mẫu thuốc mõ̃. Điều này có thể giải thích do tỉ lệ chất diện hoạt và chất đồng diện hoạt của mẫu vi nhũ tương $\mathrm{A} 2$ chỉ là $50 \%$, thấp hơn tỉ lệ này ở hai mẫu $A 1$ và $A 1^{\prime}$ là $60 \%$. Măc dù ở hai mẫu vi nhũ tương $A 1$ và $A 1^{\prime}$ có tỉ lệ $\mathrm{CDH}$ : $\mathrm{C} Đ D H$ là khác nhau nhưng khả năng giải phóng dược chất qua da chuột không khác nhau đáng kể. Điều này cho thấy cả hai chất diện hoạt và chất đồng diện hoạt ngoài tác dụng giúp vi nhũ tương hình thành và ổn định[1] chúng còn có khả năng cải thiện tốc độ giải phóng dược chất qua da. Kết quả này phù hợp với những nghiên cứu trước đó của Surajit Das và cộng sự (2020) [4] và Neslihan Üstündag `Okur và cộng sự (2011) [5] đều cho thấy các công thức VNT cho tốc độ giải phóng dược chất qua màng in vitro hay qua da chuột nhanh hơn so với chế phẩm đối chiếu trên thị trường chứa dược chất tương ứng. Từ kết quả trên có thể sơ bộ thấy rằng VNT MS có tác dụng nhanh hơn trong giảm đau cấp (6h đầu) so với công thức thuốc mõ chứa hàm lượng dược chất tương đương. Do đó vi nhũ tương MS có tiềm năng ứng dụng trong dạng thuốc dùng qua da ứng dụng giảm đau cấp.

\section{KẾT LUÂN}

Vi nhũ tương methyl salicylat $5 \%$ có hình thức đồng nhất, trong suốt, không màu, kích thước tiểu phân khoảng 20nm, khoảng phân bố kích thước - PDI khoảng 0,2. Chỉ số khúc xạ của các mẫu vi nhũ tương methyl salicylat nằm trong khoảng $1,415-1,428$. Phần trăm methyl salicylat giải phóng qua da từ vi nhũ tương $A 1$ và $A 1^{\prime}$ tăng nhanh trong $6 \mathrm{~h}$ đầu và cao hơn 1,3 lần so với thuốc mõ methyl salicylat. Như vậy VNT methyl salicylat là hệ mang thuốc qua da tiềm năng sử dụng trong giảm đau cấp.

\section{TÀI LIẸU THAM KHẢO}

1. Trân Thị Hải Yến, Hoàng Thục Oanh, Vũ Thị Thu Giang (2020), "Nghiên cứu xây dựng công thức vi nhû̃ tương methyl salicylat", Tạp chí khoa hoc Y Dược, 36(1), 30-38.

2. Attwood D, Microemulsions as drug delivery systems. 1994, Marcel Dekker, New York.

3. Bucholtz Anthony (1995), "Rayleigh-scattering calculations for the terrestrial atmosphere", Applied Optics, 34(15), pp. 2765-2773.

4. Das Surajit, Lee Sie Huey, et al. (2020), "Development of microemulsion based topical ivermectin formulations: Pre-formulation and formulation studies", Colloids and Surfaces B: Biointerfaces, 189 , pp. 110823 .

5. Okur Neslihan Üstündağ, Apaydın Şebnem, et al. (2011), "Evaluation of skin permeation and anti-inflammatory and analgesic effects of new naproxen microemulsion formulations", International journal of pharmaceutics, 416(1), pp. 136-144.

6. Yen Tran Thi Hai, Giang Tran Ngoc et al. (2020), "Niosomes loaded with diclofenac for transdermal administration: physico-chemical characterization, ex-vivo and in-vivo skin permeation studies". Journal of applied pharmaceutical science, 10(12), pp.053-061. 